\title{
Contribution of Dimensional Coordination to Construction Waste Reduction
}

\author{
Burcu Salgin* \\ Department of Architecture, Erciyes University, Turkey
}

*Corresponding author: Burcu Salgin Department of Architecture, Faculty of Architecture, Erciyes University, Kayseri, Turkey, Tel: 00903522076666 / 35207 ;

Email: bsalgin@gmail.com

\section{Editorial \\ Volume 2 Issue 1}

Received Date: January 11, 2019

Published Date: January 21, 2019

DOI: $10.23880 /$ oajwx-16000114

\section{Abstract}

The construction industry produces waste while consuming resources. To cope with the adverse effects of construction waste, attention should be focused on waste reduction opportunities. The consensus is that the architectural design decisions play an important role in construction waste minimisation. This means that any improvement in terms of architectural design decisions has the potential to enhance the construction industry's performance with construction waste-reducing benefits. To this end, this study aims at presenting an approach in construction waste optimization through dimensional coordination at the architectural design stage. To achieve the objective of the study, a residential project was chosen as a case. Finding out the most dimensionally efficient product for the bathroom flooring in this project was aimed. When determining the ceramic tile, the main criterion was to find out the most compatible size of ceramic tile which directly affects the amount of waste produced. Some calculations were made and the results of which were compared. The results show that the waste rate can be reduced to a dramatically low level when the dimensionally coordinated product is chosen for the given space. This result proves that dimensional coordination between building product and building dimensions has an important effect on waste reduction.

Keywords: Waste Reduction; Building Product; Building Dimensions

\section{Introduction}

Architectural design is a multi-criteria decisionmaking process. All decisions taken during the design stage are inputs to the construction stage. Accordingly, successful results are obtained in the cases where the decisions regarding the structural system and building products are taken in coordination with the spatial organization. Decisions as to the spatial organization are taken by the architect whereas the ones regarding the structural system are taken not merely with the Architect but also with the civil engineer. Having said that, the building products are not always selected by the Architect. Sometimes the product selection is made by other stakeholders (contractor, user, and so forth) without the architect's suggestion. Building product decisions should be taken in accordance with various criteria for effective and sustainable usage. The harmony of the building 
product with the space in terms of functional, visual and dimensional aspects is significant. Product choices made by merely aesthetic or economic concerns, without considering coordination between building and product dimensions cause mandatory cut-offs during construction, thus resulting in construction waste. On the grounds that construction waste is a major problem in the developed/developing countries and is becoming an increasing problem around the World, it is thought that dimensional coordination in building design will help to reduce construction waste. In response to growing attention to the reduction of construction waste, this study aims at presenting an approach in construction waste optimization through dimensional coordination at the architectural design stage. Gavilan and Bernold; Craven, Okraglik and Eilenberg; Osmani, Glass and Price; Salgin; Hung and Kamaludin also explained the importance of dimensional coordination in construction waste prevention [1-5].

In this study, a residential project ${ }^{1}$ which was designed in Kayseri/Turkey was selected as a case study. In the aforementioned project, different sizes of ceramic tiles for bathroom flooring are calculated in terms of waste generation. When determining the bathroom ceramic, the main criterion was to find out the most compatible size of ceramic tile which directly affects the amount of waste produced. To find out the most dimensionally efficient product, some calculations were made, the results of which were compared. Even in the example of the bathroom, which is one of the smallest units of a building, the waste rate can be reduced to a dramatically low level when the dimensionally coordinated product is chosen for the given space. It is assumed that the waste rate will be reduced if a similar method is adopted for larger spaces.

\section{Dimensional Coordination between Building and Building Product}

It is important to choose dimensionally coordinated products with the building so as to avoid the required cutoffs in the construction stage. At the architectural design stage, having determined the product options in different sizes, the dimensions of the space and the product should be associated. In order to use as many full products as possible, the appropriate size product should be selected. For example, while choosing the correct flooring option to

${ }^{1}$ The project which is numbered 052374 has been approved by Erciyes Technopark. The architectural design team of the mentioned residential project consists of Kemal Demir, Ozan Binboga, Burcu Salgin and Baris Ergen. meet the needs of each space, it is important that the dimensions of the space be coordinated with the product sizes to be used.

Assuming that;

Full tile size: $\mathrm{A} x \mathrm{~A}^{\prime}$

Cut tile size: $Y \times Y^{\prime}$

Number of full tile: $n$

Number of cut tile: $m$

Joint gap wide: $S$

Number of joint gaps: $n+m+1$

The calculation formula is as follows [6];

$$
(A \times n)+[(n+m+1) \times S]+(Y \times m)
$$

\section{A Residential Project as a Case Study}

A calculation was carried out to determine the most suitable size for the ceramic tiles planned to be used in a (140x280) cm bathroom area (highlighted in yellow in the Figure 1) in the residential project designed in Melikgazi district of Kayseri province ${ }^{2}$.

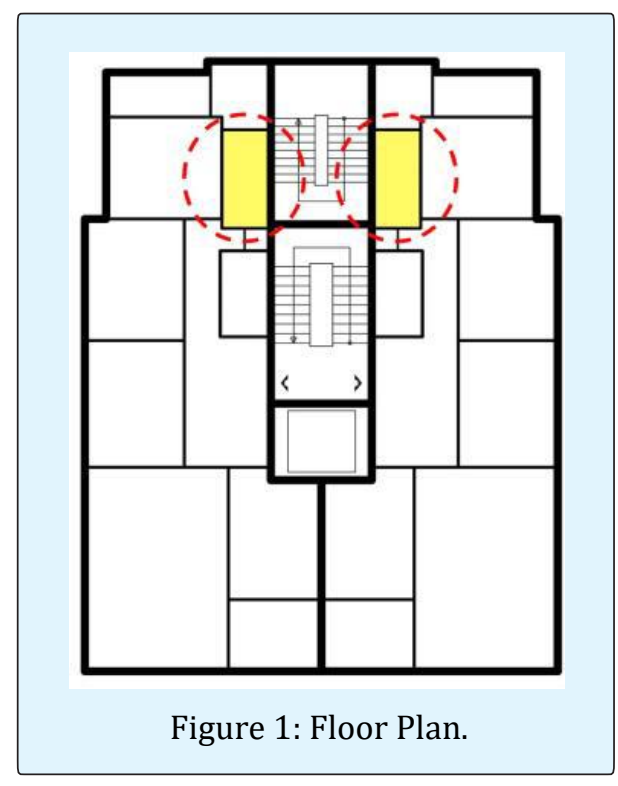

The data related to the space and building product (20x20 cm ceramic tile)-on the direction of $140 \mathrm{~cm}$-are as follows;

- Width of the floor: $140 \mathrm{~cm}$

- Number of full tile: $\mathrm{n}$

${ }^{2}$ Block number: 12024, Parcel number: 5. 


\section{Open Access Journal of Waste Management \& Xenobiotics}

- Number of cut tile: 1

- Cut tile size: $Y$

- Joint gap wide: $0,3 \mathrm{~cm}$

- Number of joint gaps: $n+1+1$

In the light of these data; calculation formula is as follows;

$$
(20 \times \mathrm{n})+[(\mathrm{n}+1+1) \times 0,3]+\mathrm{Y}=140 \mathrm{~cm}
$$

In this formula, it is possible to start calculation by giving a possible value for $\mathrm{n}$. If it is accepted as 6;

$(20 \times 6)+[(6+1+1) \times 0,3)]+Y=140 \mathrm{~cm}$ $\mathrm{Y}=17.6 \mathrm{~cm}\left[(2,4 \times 20 \times 13) \mathrm{cm}^{2}\right.$ ceramic tile waste is formed in this direction].

The data related to the space and building product -on the direction of $280 \mathrm{~cm}$ - are as follows;

- Length of the floor: $280 \mathrm{~cm}$

- Number of full tile: n'

- Number of cut tile: 1

- Cut tile size: $\mathrm{Y}^{\prime}$

- Joint gap wide: $0,3 \mathrm{~cm}$

- Number of joint gaps: n' $+1+1$

In the light of these data; calculation formula is as follows; $\left(20 \mathrm{x} \mathrm{n}^{\prime}\right)+\left[\left(\mathrm{n}^{\prime}+1+1\right) \times 0.3\right]+\mathrm{Y}^{\prime}=280 \mathrm{~cm}$

In this formula, it is possible to start calculation by giving a possible value for $\mathbf{n}^{\prime}$. If it is accepted as 13 ;

$$
(20 \times 13)+[(13+1+1) \times 0,3)]+Y^{\prime}=280 \mathrm{~cm}
$$

$Y^{\prime}=15,5 \mathrm{~cm}\left[(4,5 \times 20 \times 6) \mathrm{cm}^{2}\right.$ ceramic tile waste is formed in this direction].

The ceramic quantity for flooring according to the obtained data is as follows;

$$
\begin{gathered}
(20 \times 20 \times 6 \times 13)+(15,5 \times 20 \times 6)+(17,6 \times 20 \times 13)+ \\
(15,5 \times 17,6)=37908,8 \mathrm{~cm}^{2}
\end{gathered}
$$

The wasted ceramic is as follows;

$$
\begin{gathered}
(2,4 \times 20 \times 13)+(4,5 \times 20 \times 6)+[(20 \times 20)-(17,6 \times 15,5)]= \\
1291,2 \mathrm{~cm}^{2}
\end{gathered}
$$

$37908,8+1291,2=39200 \mathrm{~cm}^{2}$ total ceramic tile, $(1291,2 \times 100) / 39200=3,29 \%$ percentage of the ceramic waste.

In case of using ceramic tiles in the same space as $(30 \times 30) \mathrm{cm},(33 \times 33) \mathrm{cm},(40 \times 40) \mathrm{cm},(45 \times 45) \mathrm{cm}$ and $(60 \times 60) \mathrm{cm}$, the waste rates are also calculated (Table 1).

\begin{tabular}{|c|c|c|}
\hline Sizes of Tiles & 1 $^{\text {st }}$ Calculation $^{\mathbf{3}}$ & 2 $^{\text {nd }}$ Calculation $^{\mathbf{4}}$ \\
\hline $20 \times 20 \mathrm{~cm}$ & $\mathbf{3 , 2 9 \%}$ & $\mathbf{3 , 2 9 \%}$ \\
\hline $30 \times 30 \mathrm{~cm}$ & $15,02 \%$ & $7,63 \%$ \\
\hline $33 \times 33 \mathrm{~cm}$ & $21,88 \%$ & $14,26 \%$ \\
\hline $40 \times 40 \mathrm{~cm}$ & $14,17 \%$ & $\mathbf{3 , 8 8 \%}$ \\
\hline $45 \times 45 \mathrm{~cm}$ & $32,19 \%$ & $\mathbf{5 , 0 6 \%}$ \\
\hline $60 \times 60 \mathrm{~cm}$ & $28,49 \%$ & $10,61 \%$ \\
\hline
\end{tabular}

Table 1: Calculations for Ceramic Tile Waste which is used in $(140 x 280) \mathrm{cm}$ Bathroom Floor.

In the list of wastage rates, the acceptable rate for ceramic tile wastage during construction is given as $5 \%$ [7]. In practice, this ratio is acceptable if it is between 5\% and $7 \%$. In the light of these data, the $(20 \times 20) \mathrm{cm},(40 \times 40)$ $\mathrm{cm}$ and $(45 \times 45) \mathrm{cm}$ tiles are suitable for this bathroom; however, (20x20) cm tile is found to be the most compatible one -with the lowest waste rate- for this bathroom.

\section{Conclusion}

In general, dimensional coordination can be interpreted as a comprehensive approach to the coordination of building geometry and building products through a set of dimensional preferences including tolerances. This approach is a way of optimization in terms of building products. Thus, it helps construction waste reduction. In order to achieve this goal, it is important for architects to create product options of different sizes at the design stage. For each option, the product's dimensions should be analyzed. Options should be examined based on waste generation conditions. The most suitable product in terms of waste generation at acceptable limits should be selected. In this way, it is believed that environmental benefits will be achieved, and economic losses will be reduced.

\section{References}

1. Gavilan RM, Bernold LE (1994) Source Evaluation of Solid Waste in Building Construction. Journal of Construction Engineering and Management 120(3): 536-552.

\footnotetext{
${ }^{3}$ In the first calculation; it is accepted that one ceramic tile is cut once and the remaining part is considered to be completely waste.

${ }^{4}$ In the second calculation, it is accepted that one ceramic tile is cut multiple times. After the first cut, the remaining piece is cut to a smaller size and is used once again, thus reducing the amount of waste.
} 
2. Craven DJ, Okraglik HM, Eilenberg IM (1994) Construction Waste and a New Design Methodology, Sustainable Construction: Proceedings of the 1st Conference of CIB TG16, 89-98, 1994, Tampa, Florida.

3. Osmani M, Glass J, Price ADF (2008) “Architect's Perspectives on Construction Waste Reduction by Design". Waste Management 28(7): 1147-1158.

4. Salgin B (2015) Design Approaches to Prevent/Reduce C\&D Waste Generated Through the Building Life Processes and a Model Suggestion, PhD dissertation, Graduate School of Naturel and Applied Science, Architecture-Construction Program, Ylldız Technical University, Istanbul, Turkey.
5. Hung FC, Kamaludin N (2017) Professionals' Views on Material Wastage Level and Causes of Construction Waste Generation in Malaysia. Malaysian Construction Research Journal 21(1): 3354 .

6. Biçer Ozkun U (2011) A Model Suggestion to Prevent Losses on Building Products. PhD dissertation, Graduate School of Naturel and Applied Science, Architecture-Construction Program, Yıldız Technical University, Istanbul, Turkey.

7. Ankara Chamber of Commerce (ACC) (2011) Wastage Rates in Public Construction Works, pp: 1-64. 